\title{
Matrix macromolecules and Ca- phosphate components in the organophosphate-shelled biominerals
}

OLUWATOOSIN B. A. AGBAJE

MACQUARIE UNIVERSITY, Uppsala University

Presenting Author: toosin91014@gmail.com

Matrix macromolecules and Ca-phosphate components in the organophosphate-shelled biominerals

Oluwatoosin B. A. Agbaje ${ }^{\mathrm{a}, \mathrm{b}, \mathrm{c}_{*}}$, Glenn A. Brock ${ }^{\mathrm{c}, \mathrm{d}}$, Zhifei

Zhang $^{\text {d, }}$, Simon C. George ${ }^{\mathrm{b}}$, Lars E. Holmer ${ }^{\mathrm{a}, \mathrm{d}}$

${ }^{a}$ Department of Earth Sciences, Palaeobiology, Uppsala University, Uppsala, Sweden. *toosin.agbaje@mq.edu.au; toosin91014@gmail.com

${ }^{\mathrm{b}}$ Department of Earth and Environmental Sciences and MQ Marine Research Centre, Macquarie University, Sydney, Australia.

${ }^{\mathrm{c}}$ Department of Biological Sciences, Macquarie University, Sydney, Australia.

${ }^{\mathrm{d} S t a t e}$ Key Laboratory of Continental Dynamics, Shaanxi Key Laboratory of Early Life \& Environments, Department of Geology, Northwest University, Xi'an, China.

The organophosphate-shelled brachiopods such as Lingula and Discinisca are invertebrate animals that are used as paleoenvironmental proxies due to their enviably complete fossil record and their sporadic distribution in modern oceans [1]. Despite their palaeontological importance, the growth mechanism of brachiopod shells is still poorly understood. How submicron growth of calcium phosphate processes are influenced by the brachiopods physiology, needs to be answered. The organic matrix exerts a great degree of crystallographic control over the nucleation and growth of mineral particles, so detailed structural and molecular analyses of the key components of organic biopolymers are very topical.

Here, recently-alive (modern) linguliform brachiopod shells and small shelly fossils (SSFs) from the lower Cambrian have been studied by FEG-SEM, micro-Raman spectroscopy, attenuated total reflectance-FTIR, inverted light fluorescence microscopy, and thermal gravimetric analysis. For the first time, collagen is shown to be the predominant matrix protein in $\mathrm{Ca}$ phosphate components of brachiopod shells within the extracellular matrix. In the same way as nanocrystal growth is important in the formation of vertebrate biominerals, in invertebrates (specifically, brachiopods) shell biominerals grow as nanocrystals. The submicron grains of biominerals permeate the framework of chitin fibrils. The weight percentage of carbonate content of the shells are comparable with data for vertebrate skeletons. The results allow new insights into shell ultrastructure at the submicron scale, and further our understanding regarding the compositions of inter-crystalline and intra-crystalline organic macromolecules, both in modern shells and SSFs. The results show that biomolecules can remain chemically stable through geological time for paleoclimatic and paleoecological information to be derived from stable isotope analyses. 